American Journal of Software Engineering and Applications
2019; 8(2): $44-49$
http://www.sciencepublishinggroup.com/j/ajsea
doi: 10.11648 /j.ajsea.20190802.12
ISSN: $2327-2473$ (Print); ISSN: $2327-249 \mathrm{X}$ (Online)

\title{
Multimodal Instructional Approach: The Use of Videos, Games, Practical and Online Classroom to Enhance Students' Performance in Programming Languages
}

\author{
Ismail Olaniyi Muraina ${ }^{1}$, Adegboyega Adegboye ${ }^{1, ~}$, Michael Abejide Adegoke ${ }^{2}$, \\ Joseph Bankole Olojido ${ }^{3}$ \\ ${ }^{1}$ Department of Mathematical Science, Achievers University, Owo, Nigeria \\ ${ }^{2}$ Department of Computer Science, Bells University, Ota, Nigeria \\ ${ }^{3}$ Department of Computer Science \& Engineering, Rufus Giwa Polytechnic, Owo, Nigeria
}

Email address:

niyi2all@yahoo.co.uk (I. O. Muraina), akanbi2090@yahoo.co.uk (A. Adegboye), adegoke 98@yahoo.co.uk (M. A. Adegoke), olojidoj@gmail.com (J. B. Olojido)

${ }^{*}$ Corresponding author

To cite this article:

Ismail Olaniyi Muraina, Adegboyega Adegboye, Michael Abejide Adegoke, Joseph Bankole Olojido. Multimodal Instructional Approach: The Use of Videos, Games, Practical and Online Classroom to Enhance Students' Performance in Programming Languages. American Journal of Software Engineering and Applications. Vol. 8, No. 2, 2019, pp. 44-49. doi: 10.11648/j.ajsea.20190802.12

Received: October 23, 2019; Accepted: November 20, 2019; Published: November 26, 2019

\begin{abstract}
Multimodal teaching and learning via visual (video), sound (music), movement (amination), print-based text, and technology for students has great impact on content delivery if teachers teaching programming language realize its potency. Inclusion of multimodality in curriculum would enhance diversity of learning process. In this study, the author looked into the use of different modes of approaches (Multimodal Approaches) to produce desired result better more realistic and dynamic to the use of a single (monomodal) approach or mode. The study exposed students to the use of: video mode, game mode, practical mode and online classroom mode in learning a programming language. The degree students formed the target population. Data collection was done in three bases: paper data collection for videos and games, practical data for the practical classes while data was collected electronically for online classroom respectively. Quantitative analysis results of the data revealed that employing multiple modes (multimodality) for instructional supports to enhance learning programming language gave teachers opportunities to help them gain nuanced understanding of codes, powerfully express what they learned, and discover a psychological refuge. Importantly, multimodal teaching approach was found to enhance programming sense of accomplishment and self-esteem.
\end{abstract}

Keywords: Multimodal, Teaching, Learning, Programming Language and Classroom

\section{Introduction}

Learners in all ramifications are not the same. Each student in a classroom has a unique and complex system of thinking and learning. So, we cannot assume that we should teach the students alike. As an effective teacher, it is important and necessary for teacher to know better ways to reach their students. Solutions might best be found by combining different teaching modes available and relevant instead of a one-way approach. Multimodal approaches like the use of videos, games, practical, online classroom and materials are such modes that when applied together will bring robust learning opportunities to students and also make it possible for multimodal student's assessment interpretations. This paper points out that a multimodal approach can improve interaction between teachers and learners, learners and input materials, and smooth classroom communication in general. In order to ensure smooth interaction and optimizing communication by appropriate selection and combination of modes by the teacher provides a framework for creative learning [11]. Principally, in the teaching and learning programming language in higher institution, multimodal approach to 
learning offers a springboard to satisfy all learning styles and cognitive differences, as well as to achieve individual and general aims and objectives of teaching and learning process. The study contributes to the knowledge by looking multiple ways a programming language can be taught and learnt rather than looking at one or two ways which may not encompass series of human organs and skills development. This combination (use of multiple modes) allows for creativity and flexibility in teacher-student interaction and can enhance the learning environment [11]. One of the limitations of this study is using multimodal approaches to just only pascal programming language. The below research questions will guide the study:

a. Is there any significant difference between the pre-test performance of students and post-test performance of students after exposing them to multimodal approaches such as videos, games, practical skills and online classroom?

b. Are there any significant contributive effects of multimodal approach to effective teaching and learning of programming language(s)?

\section{Related Literature}

\subsection{Combining Teaching Modes Approach}

Teaching modes such as watching videos, playing games, doing real practical, and online classroom are powerful approaches to teach programming language and in various ways to facilitate learning in higher institutions. By integrating different modes together better understanding will set in because of dynamic nature of teaching presented by the teacher. Teachers who understand the cognitive-socialemotional state of students' brains can enrich the learning environment by differentiating their instruction with multiple modes of teaching. If teachers strive to maintain a balance of differentiated quality instruction with an atmosphere of risktaking and emotional safety, they up the odds that students will find success in school. By incorporating multiple modes of instruction that build up their students' schema and when they present information in a socially and an emotionally safe climate, students attend to their learning with a higher degree of accuracy, retention, and confidence.

\subsection{History of Multimodality}

Multimodality has developed as a theory throughout the history of writing. The idea of multimodality has been studied since the 4th century BC, when classical rhetoricians alluded to it with their emphasis on voice, gesture, and expressions in public speaking. However, the term was not defined with significance until the 20th century. During this time, an exponential rise in technology created many new modes of presentation. Since then, multimodality has become standard in the 21 st century, applying to various networkbased forms such as art, literature, social media and advertising. The monomodality, or singular mode, which used to define the presentation of text on a page has been replaced with more complex and integrated layouts. John A. Bateman says in his book Multimodality and Genre, "Nowadays... text is just one strand in a complex presentational form that seamlessly incorporates visual aspect 'around,' and sometimes even instead of, the text itself. Multimodality has quickly become "the normal state of human communication.

\subsection{Multimodal Teaching Approach}

Multi-modal tools are approaches to help students' brains function better in relation to the information upon which they are required to work [11]. It is important to remember that all aspects of a classroom present perceived visual, audio, and somatosensory stimuli to the student at the same time their own memories and physical states create internal distractions. A classroom, a teacher, and a set of instruments and peers are all part of the sensory field. To help students attend to new information, it is useful to create a variety of stimuli modes to which they can attend, often accessing different modes at different times over the course of a lesson or assignment. Each mode allows the student to connect any given concept to a different aspect of sensory memory. Multimodal teaching approaches includes: videos, games, practical and online classroom which are discussed fully below:

\subsection{Videos (Visual)}

Using video in the classroom encompasses a variety of modes, primarily visual, and can exclude or include text as required by the teacher and dependent on the teacher's choice [11]. There is also great choice available in the audio or speech modes, and finally the mode of movement which occurs within the video. For example, there is an exciting possibility offered by data-quest, which is a combination of text, movement, sound with or at times without image. The teacher's conscious decision in selecting and evaluating material is fundamental in the development of critical awareness of the visual media by both teachers and students alike [11]. The choice of video for the sample lesson featured several crucial input characteristics, exemplified in the visual, text and audio modes. Any kind of an instruction whether in public schools, private schools or informal education is an existing activity which is in need of enhancement of educational atmosphere particularly visual learning aids [3]. The visuals were social semiotic icons, which are easily recognizable by a large audience, using very little text but providing prompts and enough background factual information to state the argument clearly, coupled with a lively, cheerful tune attracting and maintaining attention throughout the minute or so length of the video. The significance of the choice of suitable input material ultimately lies with the teacher but can easily be extended to students, who can participate in choosing suitable materials with the teacher's guidance. Interest and purpose are essential ingredients and necessarily ought to fit in with curricula and institutional requirements as well as immediate and longterm objectives. 


\subsection{Audio (Sound)}

According to [17] audio cassette and discs serve as main material and /or support materials for distance learning because these audio media can be played back as many times as possible to the inflexibility of the radio. The benefits of audio media are numerous; they include: the materials can be used at any time the learner wants to use them, the recorded media can be stopped and played back at will and by choice, and any material that is not necessary can be skipped.

Audio media have created landmarks where printed materials are faulted. [17], also observed that recording and presentation of subject like programming language can be done using audio by presenting raw sounds of subject for study. For instance, by recording the steps taken by teacher and replay it back at a convenient time. This means that it can used to record the correct or satisfactory form of articulation - as in Programming Language Teaching. Poullinus added that it is much easier within the new audio disc because the learner can locate a particular sound on the disc with ease without the burden of playing back the entire tape as when using audio tapes. The students are at liberty to regulate what to play and how many times to repeat what playing. The advantages of audio media also extend to the learning of how some scientific terms or words are to be pronounced. According to [1], audio recordings carry messages which are intended to be decoded by the receiver with the sense of hearing. He further his statement that audio recordings can be used to prepare rich instructions. Audio recordings are very useful, very versatile in instructions. It can be used to introduce, present the lesson in a clear form, and evaluate lessons. Recordings from audio are very useful in individualized/ self-paced learning. A slow learner, could play several times on audio recordings without the machine becoming impatient [1]. [2], asserted that teachers can record classroom activities such as dramatization, interviews or discussions and play them back later or during other sessions. It means that teachers can record voice coding or steps in the form of audio from educational radio programs either from a normal classroom work or for the use of their students, either individually or in small groups. Uses of audio recording do not have limitation unless the teacher could not think of applying it in teaching and learning process. [1], posited that the audio tapes could be prepared by teachers to meet specific instructional purposes in any subject area. Students could also record teachers' presentations during the lessons for later reviews. [21], opined that audio tapes enable learners to: use the material at any time they choose, stop and start the sound at will, replay a passage as often as they wish and skip over any material that they do not need

\subsection{Practical (Showing Skills)}

Programming is a fundamental skill that all computer science students are required to learn. Therefore, programming as a course is always be regarded as most difficult subject/course and often have the highest dropout rates [15] and [19]. Literatures have pointed out the modes of teachers used in imparting programming languages courses to the students. A mono-mode is not sufficing to teach programming language in computer science. The common programming languages like: $\mathrm{C}++, \mathrm{C} \#$, Java, Python, Ruby, Visual-Basic etc. require multimodal approaches for effective understanding and dynamic presentation of the courses/subjects to meet different needs of students. Difficulties in understanding even the most basic concepts such as variables, data types or memory addresses as these abstract concepts could be as a result of using a single mode of teaching it instead of multimodal approaches [19] and [13]. The benefit of using multimodal approaches to teaching programming languages is that it allows students to be involved and at the same time have the ability to develop an intuitive understanding of basic concepts in a visual feedback environment [4]. Thus, students using practical mode as well as their teacher make a great progress in coding and build in them ability to carry out such action individually. It seems natural, and rather obvious, that learning programming language in computer science should involve seeing, handling and manipulating real objects and materials, and that teaching programming will involve acts of 'showing' as well as of 'telling'. That is why practical work is so important in programming language.

\subsection{Online Classroom (Visual, Audio and Showing Skills)}

As one plans online course, it is helpful to remember that in any environment "good teaching is good teaching" [18]. In order to understand student performance in the typical online course, it would be most useful to compare a large and representative set of online courses against a similar set of face-to-face courses. Online classroom mode of teaching is more advantageous compared to face-to-face type of instruction. However, many studies in programming like: Sololearn, Coursera, Microsoft, Alison, FutureLearn, Dataquest etc. have made this possible since learning can occur "Synchronously" and "asynchronously': anytime, anywhere, anyplace [2]. For many institutions, online education is creating an interesting paradox. [14], argues that online education is very different from traditional classrooms, which have a tendency to be dominated by the instructor with limited student interaction. As such, online learning has created a new paradigm in respect to the way in which people perceive the teaching and learning process [14]. According to [10], over the past 20 years the number and variety of instructional approaches and course delivery modes, especially online, available to instructors has increased. Online classroom incorporates other modes of teaching and learning. It includes: Visual learning mode, Audio learning mode and Practical based mode, all these embedded multimodes in online classroom are useful and relevant to make teaching and learning programming language more pleasurable and interesting.

\section{Related Work}

Fang-o et al [6], presents Develop and evaluate the effects 
of multimodal presentation system on elementary student learning effectiveness: within classroom English learning activity. The research work develops a multimodal presentation software integrated with interactive whiteboard (IWB) as a multimodal presentation system (MPS) to support the classroom English learning in the elementary English as second language (ESL) course. An experimental research designed was conducted. At the end of the learning students took a post-test for measuring the learning achievement and questionnaires for measuring the learning. Evaluation was done using t-test. The empirical analysis results reveal that the students who used the multimodal presentation system (MPS), a multimodal presentation software integrated with interactive whiteboard (IWB), obtained a better result on average, this implying that the system is able to lead students to significantly better learning achievement in English vocabulary learning. There is need to carry similar research work using Programming language and student from different education environment in order to generate empirical evidence with greater generalization.

Fawaz and Ahmad [7] presented Enhanced Teaching Model (ETM) for Teaching Programming Languages. The research work was motivated by the expectations from the industry, to have students and employees who are independent and capable of quickly writing code to resolve work-related issues. The research work examined the necessary gap that need to be filled in the area of teaching approach, teaching model and teaching tool used in impact programming language to student Meta-analysis research methodology was adopted in this research work. The research work proposed Enhanced Teaching Model (ETM) which combines several teaching approaches and models from literature. However, the model is not implemented.

In Rosihan Ari and DwiMaryono [20], Robomind Utilization to Improve Student Motivation and Concept in Learning Programming was presented. The aim of the study is how to utilize robomind as a tool to motivate students in learning computer programming. Robomind is a programming assistance software tool used for programming concept learning, logical thinking and problem solving. This research work is motivated by the lack of student motivation in learning programming that caused by the initial perception that programming is difficult. In the research methodology students are introduced to Robimind as the first material before Pascal programming language. The research worked evaluation was based on use of Robomind in learning programming. There is need to employ other assistance software tool used for learning programming concept. The programming language should not be limited to Pascal programming language. Other programming language and evaluation method should be employed.

Parisa Kordjamshidi [16] presented Spatial Language Understanding with Multi modal Graphs using Declarative Learning based programing. The aim of the research work is to extract formal spatial meaning from text. The work exploited visual information in the form of images to enhance spatial language understanding. The research work is limited to Declarative based programming and spatial language understanding. The coding aspect of the used declarative based programming is absent. There is need to involve coding aspect of the declarative and other computer programming language in this work.

Mia Heikkilä [12] presents Debugging in Programming as a Multimodal Practice in Early Childhood Education Settings. The aim of this research work is how programming can be understood in preschools, focusing specifically on debugging as one of the phases involved in learning to program. This study contributes to the knowledge base on aspects that need to be considered when planning and carrying out programming related teaching activities in a preschool setting. However, there is need for exploits other phases of programming language in this study. The methods in this research are both analogue (also called unplugged activities), such as programming using verbal instructions or cards, and tasks that involved some digital equipment, such as small robots (Bluebots) and iPads.

In a study [5], A Multimodal Approach for Programming Intelligent Environments was presented. The aim of the research work is to Provides end-users with tools suitable for programming intelligent environment. The methodology approach used is a multimodal chatbot that permits end users to create simple "if-then" rules to define the behavior of an intelligent environment. The research work is limited to end user in intelligent programming environment and IF-THENRULES aspect of programming coding style. There is need to extend this work to include other aspect of programming coding style and other computer programming environment.

\section{Methodology}

The study examined 35-degree students currently studying "Pascal Programming Language"using four multimodal approaches such as: Video, Game, Practical and Online Classroom. They were all exposed to pretest of 20 multiple questions covering all aspects of the course. Video recordings were prepared to teach steps required in code and series of example in coding, after which questions were asked to test their level of retention in the course. Since the teaching is using multimodal approaches, the teacher also exposed the students to coding games such as: CodinGame, CodeCombat, Screeps etc. though it limited us to some languages like java C\#, Python languages whereas the core programming language used was Pascal as contained in the curriculum. We also used pure practical session to teach the same concept (Pascal Language) and finally, we used online classroom created to give the students chance to post and comment on solving series of problems in Pascal programming language. The multimodal assessments were also used to collect data from the students like: Multiple choice questions for videos, report writing on games played, solving questions in real practical using computers in the laboratory and using assignment and test online classroom via Google classroom as post-test. 
Table 1. Paired Samples Statistics.

\begin{tabular}{llllll}
\hline & & Mean & N & Std. Deviation & Std. Error Mean \\
\hline \multirow{2}{*}{ Pair 1 } & Pretest & 39.2286 & 35 & 12.23324 & 2.06779 \\
& Video_Posttest & 80.6286 & 35 & 9.47469 & 1.60151 \\
\multirow{2}{*}{ Pair 2 } & Pretest & 39.2286 & 35 & 12.23324 & 2.06779 \\
& Game_Posttest & 65.5143 & 35 & 9.02080 & 1.52479 \\
\multirow{2}{*}{ Pair 3 } & Pretest & 39.2286 & 35 & 12.23324 & 2.06779 \\
& Practical_Posttest & 89.0571 & 35 & 3.97006 & .67106 \\
Pair 4 & Pretest & 39.2286 & 35 & 12.23324 & 2.06779 \\
& Online_Class_Posttest & 76.7429 & 35 & 11.39232 & 1.92565 \\
\hline
\end{tabular}

Table 2. Paired Samples Correlations.

\begin{tabular}{lllll}
\hline & N & Correlation & Sig. \\
\hline Pair 1 & Pretest \&Video_Posttest & 35 & -.104 & .553 \\
Pair 2 & Pretest \&Game_Posttest & 35 & .355 & .037 \\
Pair 3 & Pretest \&Practical_Posttest & 35 & .235 & .174 \\
Pair 4 & Pretest \&Online_Class_Posttest & 35 & -.139 & .427 \\
\hline
\end{tabular}

Table 3. Paired Samples Test.

\begin{tabular}{|c|c|c|c|c|c|c|c|c|c|}
\hline & & \multicolumn{5}{|c|}{ Paired Differences } & \multirow{3}{*}{$\mathbf{t}$} & \multirow{3}{*}{ df } & \multirow{3}{*}{$\begin{array}{l}\text { Sig. (2- } \\
\text { tailed) }\end{array}$} \\
\hline & & \multirow[b]{2}{*}{ Mean } & \multirow[b]{2}{*}{$\begin{array}{l}\text { Std. } \\
\text { Deviation }\end{array}$} & \multirow[b]{2}{*}{$\begin{array}{l}\text { Std. Error } \\
\text { Mean }\end{array}$} & \multicolumn{2}{|c|}{$\begin{array}{l}95 \% \text { Confidence Interval } \\
\text { of the Difference }\end{array}$} & & & \\
\hline & & & & & Lower & Upper & & & \\
\hline Pair 1 & Pretest - Video_Posttest & -41.40000 & 16.23214 & 2.74373 & -46.97594 & -35.82406 & -15.089 & 34 & .000 \\
\hline Pair 2 & Pretest - Game_Posttest & -26.28571 & 12.35878 & 2.08902 & -30.53110 & -22.04032 & -12.583 & 34 & .000 \\
\hline Pair 3 & Pretest - Practical_Posttest & -49.82857 & 11.93976 & 2.01819 & -53.93002 & -45.72712 & -24.690 & 34 & .000 \\
\hline Pair 4 & Pretest - Online_Class_Posttest & -37.51429 & 17.83482 & 3.01463 & -43.64076 & -31.38781 & -12.444 & 34 & .000 \\
\hline
\end{tabular}

\section{Results/Findings}

Table 1 shows mean, standard deviation of the paired sample statistics. It was clearly shown that pretest of the students Mean is 39.2286 and standard deviation of 12.23324 were the same throughout. Video post-test has 80.63 $(\mathrm{SD}=9.47)$, game posttest has $65.51(\mathrm{SD}=9.02)$, practical post-test has 89.06 (3.97) and online classroom with 76.74 (11.39). The students performed excellently well in using different modes when compared their results with pre-test. Though, they did well more in suing practical skills and video than using online classroom and games

Table 2 reveals that all the modes of teaching are good types (video $\mathrm{P}>0.05$, practical $\mathrm{p}>0.05$ and online $\mathrm{p}>0.05$ ) except game mode that was showing that pretest and posttest had little relationship. $355(\mathrm{P}<0.05)$, this implies that the mode did not do the same work as other modes did. This happened because the students could not find "Pascal Programming Language game to play" instead they played games relating to: Python, $\mathrm{C \#}$ and Java

The last table (Table 3) displays the comprehensive result of t-test of all the paired samples. From the table all paired samples t-test were statistically significant [pretest-video posttest $(\mathrm{df}=34), \mathrm{t}=-15.089$; pretest-game posttest $(\mathrm{df}=34)$ $\mathrm{t}=-12.583$; pretest-practical posttest $(\mathrm{df}=34) \mathrm{t}=-24.690$; pretest-online classroom posttest $(\mathrm{df}=34) \mathrm{t}=-12.444$ : all have $\mathrm{p}<0.05]$.

The findings show that using multimodal approach to teaching and learning programming languages makes students have opportunity to different dynamic and useful modes to ease their understanding and to be able to have good grade in such course. This is in consonance with what [10] said that multi-modal tools are approaches to help students' brains function better in relation to the information upon which they are required to work. Also, it was observed by [4] that the benefit of using multimodal approaches to teaching programming languages is that it allows students to be involved and at the same time have the ability to develop an intuitive understanding of basic concepts in a visual feedback environment Findings have answered the two research questions successfully. The students' performance after exposing them to multimodal approach were better than the pretest performance. Also, the approach has great impact on the effective teaching and learning of programming language(s).

\section{Conclusion}

Multimodal approaches to effective teaching and learning was the major discussion in this paper. The paper supports and encourages the use of multimodal approaches because it looks at many ways to impart the knowledge to students rather than using one-way direction. The use of multimodal approaches for instructional supports to enhance programming language gave teachers opportunities to help them gain nuanced understanding of codes, powerfully express what they learned, and discover a psychological refuge. Importantly, multimodal teaching approach was found to enhance programming sense of accomplishment and self-esteem. 


\section{References}

[1] Abimbola, I. O. (2001) Fundamental Principles and Practice of Instruction Ilorin. Belodan [Nig] Enterprises \& Tunde Babs Printers.

[2] Abullahi, M.(1998) An Introduction to aspect of Educational Technology. Kano. Gidan Dabino Publishers.

[3] Andersen, N. (2009). Learning Materials for Education Excellence: University of Nairobi: Oxford Publishing House, PP 24.

[4] Dann, W., Cooper, S. \& Pausch, R. (2001). Using visualization to teach novices recursion. Proceedings of the 6th Annual Conference on Innovation and Technology in Computer Science Education. SIGCSE Bull. 33, 3 (Sep. 2001), (pp. 109-112). Canterbury: ACM. DOI=http://doi.acm.org/10.1145/507758.377507

[5] Evropi Stefanidi, Michalis Foukarakis, Dimitrios Arampatzis, Maria Korozi, Asterios Leonidis and Margherita Antona (2019): A Multimodal Approach for Programming Intelligent Environments. Proceedings of the 11th International Conference on Pervasive Technologies Related to Assistive Environments (PETRA 2019). Pp. 50-57.

[6] Fang-O Kuo, Pao-Ta Yua, Wei-Hung Hsiao (2015): Develop and evaluate the effects of multimodal presentation system on elementary student learning effectiveness: within classroomEnglish learning activity. Procedia - Social and Behavioral Sciences 176 (2015) Pp. 227 - 235. ScienceDirect Elsevier.

[7] Fawaz Alajmi and Ahmad Alkhatib (2015): Enhanced Teaching Model (ETM) for Teaching Programming Languages. International Journal of Computer Applications (0975 - 8887) Volume 121 - No. 20. Pp. 13-24.

[8] Gomes, A., Areias, C. M., Henriques, J. \& Mendes, A. (2008). Aprendizagem de programação de computadores: dificuldades e ferramentas de suporte. Revista Portuguesa De Pedagogia, $42,2,161-179$.

[9] Lahtinen, E., Mutka, K. A. \& Jarvinen, H. M. (2005). A study of the difficulties of novice programmers. In Proceedings of the 10th Annual SIGSCE Conference on Innovation and Technology in Computer ScienceEducation (ITICSE 2005). Monte da Caparica, Portugal, June 27-29, 2005 (pp. 14-18). New York: ACM Press.

[10] Lindholm, J. A., Szelényi, K., Hurtado, S., \& Korn, W. S. (2005). The American college teacher: National norms for the 2004-2005 HERI faculty survey. Los Angeles, CA: University of California, Los Angeles, Higher Education Research Institute. Retrieved from http://www.heri.ucla.edu/PDFs/pubs/ FAC/Norms/Monographs/TheAmericanCollegeTeacher2004T o2005.pdf

[11] Marchetti, L. and Cullen, P (2014) A multimodal Approach in the Classroom. Chronicle of Higher Education.

[12] Mia Heikkilä Iand Linda Mannila (2018): Debugging in Programming as a Multimodal Practice in Early Childhood Education Settings. Multimodal Technologies and Interaction. Pp 1-20.

[13] Miliszewska, I. \& Tan, G. (2007). Befriending computer programming: a proposed approach to teaching introductory programming. Journal of Issues in Informing Science \& Information Technology, 4, 277-289.

[14] Nishikant, S. (2009). The paradigm shift for adult education: from educational slavery to learning freedom of human brain with synaptic learning. In T. Kidd (Ed.), Online education and adult learning: Newfrontiers for teaching practices. Hershey, PA: IGI Global.

[15] O'Kelly, J. \& Gibson, J. P. (2006). RoboCode \& problembased learning: a non-prescriptive approach to teaching programming. In Proceedings of the 11th Annual SIGCSE Conference on Innovation and Technologyin Computer Science Education (Bologna, Italy, June 26-28, 2006) (pp. 217-221). ITICSE '06. New York: ACM.

[16] Parisa Kordjamshidi, Taher Rahgooy and Umar Manzoor (2017): Spatial Language Understanding with Multimodial Graphs using Declarative Learning based programing. Proceeding of the $2^{\text {nd }}$ Workshop on structural prediction for Natural Language processing. Pp. 33-43.

[17] Paullinus, J. E. (2006) Issues in Educational Technology. Uyo: Abam Publishing Co.

[18] Ragan (1998) Language Learning Online: Towards Best Practice. Retrieved on line $20^{\text {th }}$ May, 2017 from www.book.google.com.ng

[19] Robins, A., Rountree, J., \& Rountree, N. (2003). Learning and Teaching Programming: A Review and Discussion. Computer Science Education, 13 (2): 137-173.

[20] Rosihan Ari and DwiMaryono (2016): Robomind Utilization to Improve Student Motivation and Concept in Learning Programming. Prosiding ICTTE FKIP Vol 1, Nomor 1, Januari 2016 Halaman. Pp. 962-966.

[21] Rowntree (1991) Teaching through Selijinstruction. Retrieved on line $20^{\text {th }}$ May, 2017 from www.book.google.com.ng 